\title{
Meeting Place for Deburring Technologies
}

\begin{abstract}
In the middle of October 2021, users from various industries with a wide range of tasks in the production steps of deburring and surface finishing will be able to exchange information with suppliers in face-to-face discussions again: at the 4th Deburring Expo in Karlsruhe.
\end{abstract}

This year's Deburring Expo will be held from October 12 to 14 as an attendance event at the Trade Fair Center Karlsruhe in Germany. The integrated expert forum with simultaneously translated presentations (German $<>$ English) also enables the crucial transfer of knowledge on current developments and trends in these manufacturing sectors.

\section{Wide range of industries and technologies}

Whether it's the automotive and supplier sector, machine and equipment industry, medical device and pharmaceutical industries, measurement, precision mechanics and sensor technology, tool and mold making or energy and environmental technology - demand is booming again in many branches of industry. The component manufacturing sector, however, is facing new and changed tasks. This is due to transformation processes, different production technologies such as additive manufacturing, new and optimized materials and the trend towards the automation and digitization

\section{Deburring Expo 2021}

Info about the trade fair for deburring technologies and precision surfaces: When: 12 to 14 October 2021 Where: Karlsruhe Exhibition Center Messeallee 1 76287 Rheinstetten (Germany)

Times: $\quad$ 9:00 am to 5:00 pm (14.10.2021 to $4: 00 \mathrm{pm})$

Website: www.deburring-expo.de/en

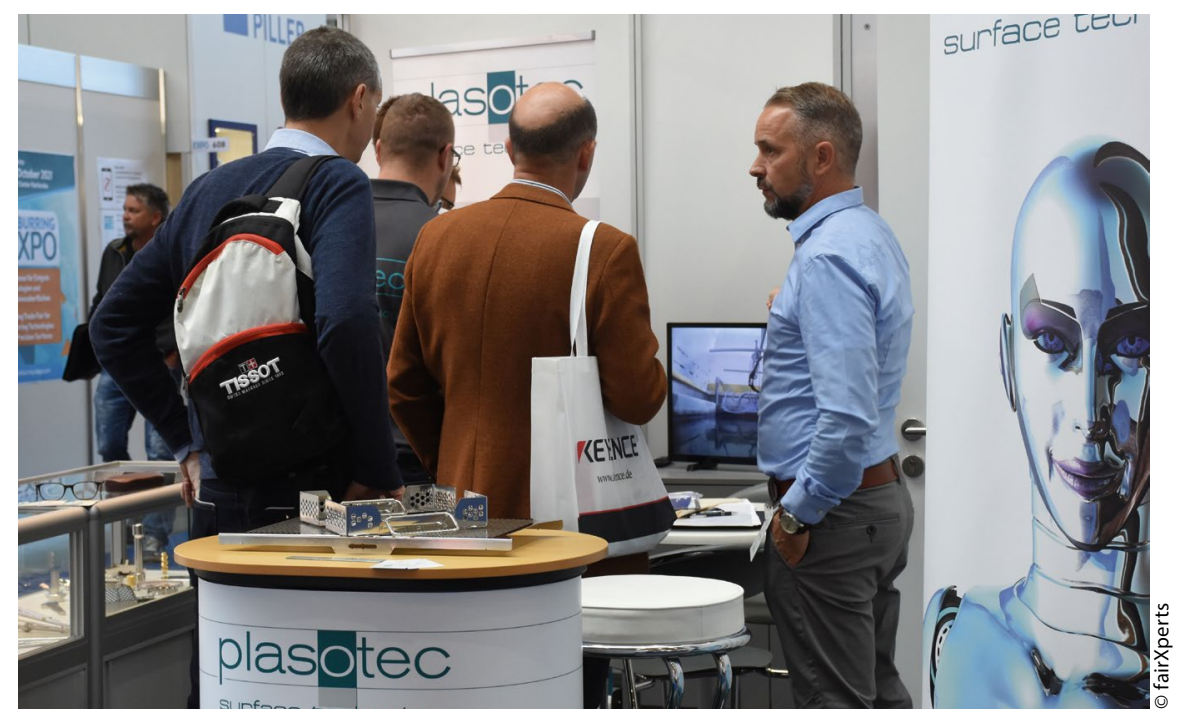

The clear focus on deburring technologies and precision surfaces enables visitors to find out about and compare a wide range of technologies and processes in person.

of production processes, as well as new regulatory requirements. As different as these may be in the various industries, burr-free and optimally-finished surfaces tailored to product specifications are playing an increasingly important role. "On the one hand, the aim is to improve quality, precision and energy efficiency in deburring and surface finishing. On the other hand, it is about reducing costs," explains Hartmut Herdin, CEO of Fairxperts and organizer of Deburring Expo, describing some of the key challenges companies are facing.

As an information and communication platform with a clear focus on deburring technologies and precision surfaces, the leading trade fair makes it possible to compare technologies and services in a targeted and efficient manner. This is also reflected in the fact that nearly all market and technology leaders are represented at Deburring Expo.

The wide offer of the fair is rounded off by the theme parks "Automated Deburring with Industrial Robots”, “AM Parts Finishing” and "Cleaning after Deburring”.

\section{Bilingual expert forum - knowledge transfer as added value}

High-quality, practice-oriented lectures ensure a valuable transfer of knowledge at the three-day expert forum integrated into Deburring Expo. The simultaneously translated (German $<>$ English) presentations will inform about basics, ways to optimize processes and costs, bestpractice applications and trends, and also about the contents of the theme parks. // 